\title{
Gender difference in suicidal ideation and related factors among rural elderly: a cross-sectional study in Shandong, China
}

\author{
Lu Lu ${ }^{1,2,3}$, Lingzhong Xu ${ }^{1,2,3^{*}} \mathbb{D}$, Xiaorong Luan ${ }^{4^{*}}$, Long Sun ${ }^{1,2}$, Jiajia Li $\mathrm{Li}^{1,2,3}$, Wenzhe Qin ${ }^{1,2,3}$, Jiao Zhang ${ }^{1,2,3}$, \\ Xiang Jing ${ }^{1,2,3}$, Yali Wang ${ }^{1,2,3}$, Yu Xia ${ }^{1,2,3}$, Yaozu Li ${ }^{1,2,3}$ and An'an Jiao ${ }^{1,2,3}$
}

\begin{abstract}
Background: Suicide is a global public health problem which has significant negative influence on individuals, families and the society. The aim of this study is to investigate the prevalence of suicidal ideation and related factors among elderly people in rural China, and further examine the gender differences of suicidal ideation.

Methods: Data were collected from the 2017 Survey of the Shandong Elderly Family Health Service, which was conducted by Shandong University. A total of 5514 elderly aged 60 and above from rural Shandong were included in this study. Binary logistic regression model was performed to examine the gender difference towards suicidal ideation, and to identify the influencing factors of suicidal ideation by gender among elderly.

Results: $7.7 \%$ rural elderly reported suicidal ideation in the past 12 months in Shandong, China. The prevalence of suicidal ideation among females was significantly higher than that among males $(P<0.001)$. Education level, debts, stress of daily life, loneliness and psychological distress were significantly related to suicidal ideation in both males and females. Besides, negative life events and life satisfaction were found to be significantly associated with suicidal ideation in females but not in males.

Conclusions: There was a significant gender difference towards suicidal ideation among rural elderly in Shandong, China. So, gender difference should be considered when medical practitioners and public health workers seek to prevent and manage suicidal ideation among rural elderly, which will be important to develop strategies for coping with risk factors for suicidal ideation among males and females. In other words, more attention should be paid to females who had encountered negative life event or with lower life satisfaction.
\end{abstract}

Keywords: Suicidal ideation, Gender difference, Rural elderly, China

\section{Background}

Suicide is a serious public health issue in the worldwide, which causes a heavy economic, social and psychological burden on the individuals, families and society.

\footnotetext{
*Correspondence: Izxu@sdu.edu.cn; luanxrong@163.com

${ }^{3}$ Center for Health Economics Experiment and Public Policy Research, Shandong University, Jinan 250012, China

${ }^{4}$ Department of Nursing Management of Qilu Hospital, Shandong University, Jinan 250012, China

Full list of author information is available at the end of the article
}

According to the World Health Organization (WHO), suicide accounted for $1.4 \%$ of all deaths worldwide, making it the 18th leading cause of death in 2016 [1]. Globally, there were an estimated 793,000 suicide deaths in 2016, which indicated an annual global age-standardized suicide rate of 10.5 per 100,000 population [2]. The WHO suicide prevention report pointed out that the prevalence of suicide in China was 7.8 per 100,000 people in 2012 [3] and ranked as the fifth leading cause of death among the general population and contributed to $42 \%$ of all suicide worldwide and $56 \%$ of the world's female suicide [4]. 
With the aging of population, the prevalence of suicide among elderly is increasingly higher, which becomes one of the most important public health issues we should of concern. A report from WHO showed that suicide rate for older adults is highest for those aged 70 years or over in almost all regions of the world [3]. Some previous studies also indicated that the elderly has the highest suicide rates [5, 6]. Another study showed that seniors aged 65 years and over had the highest rate of completed suicide in China, which reached $44.3-200$ per 100,00 [7]. It is worth noting that there are some special characteristics of suicide rates in China compared to western countries, such as the suicide rate among the rural elderly is much higher than that among the urban elderly $[7,8]$, and the rate among females is higher than that among males [4, 9]. China is one of few countries with higher female suicide rates in the worldwide, but little is to known about the gender difference in suicidal ideation among Chinese rural elderly. Therefore, suicidal ideation among Chinese rural elderly and the difference between males and females deserve more attention.

Suicidal ideation is the early process of suicide and it always presents before suicide completion. According to available evidence, suicidal ideation can be regarded as a trigger for attempted and completed suicide. Thus, understanding the potential risk factor of suicidal ideation in the initial stages of suicide is important in the suicide prevention. The prevalence of suicidal ideation in seniors in China ranges from 2.2 to $21.5 \%$, and suicidal ideation increases gradually with age in older adults [10]. Many factors have been found to be associated with suicidal ideation among older adults, including age $[11,12]$, gender and marital status [13], education level [14, 15], living arrangement [16], economic status [17], social support and depression [18], which can be classified into three groups: sociodemographic factors, socio-environmental factors and psychological factors. Besides, factors related to physical health such as chronic disease and disability $[19,20]$ were also risk factors for suicidal ideation.

Among these influencing factors, gender is one of the most significant factors which we should consider for suicidal ideation, given that gender difference in the suicide [21] and suicide attempts [22, 23] have been confirmed. Gender difference towards suicidal ideation reflects the difference not only in demographic characteristics, but also in socioeconomic circumstances and health conditions. A previous study conducted in South Korea revealed that the prevalence of suicidal ideation was higher among female adolescents than among their male counterparts [24]. Another study conducted in Malaysia showed that suicidal ideation was higher among males compared with females [25]. Similarly, a study from China mainland showed that girls were significantly more likely than boys to report both suicidal ideation and attempts [26]. Another study from China Taiwan showed that girls who reported quarrels with parents had the highest level of suicidal ideation before age 18 [27]. However, studies mentioned above mainly focused on adolescent students or young adults for gender difference in suicidal ideation. To our knowledge, only a few studies focused on older adults and there was a lack of research investigated the difference towards suicidal ideation by gender among elderly in rural China. Thus, our study aims to examine the gender difference in suicidal ideation and related factors among rural elderly in Shandong, China.

\section{Methods \\ Data and sample}

Our data were collected from the 2017 Survey of the Shandong Elderly Family Health Service, which was conducted by Shandong University. Multi-stage random sampling was applied to select participants: in the first stage, 6 counties were selected from 137 counties as the primary sampling units (PSUs) throughout the eastern, central and western regions of Shandong Province (which were divided into 3 districts and 3 counties that represented urban and rural areas separately). From each PSU, 18 villages in rural area and 18 communities in suburban and urban area were selected as the secondary sampling units (SSUs). In the third stage, based on the roster of the residents by age and the total elderly population of each selected site provided by the local residential committee, an average of 66 individuals were stratified and randomly selected from each SSU making up the total sample. The eligible participants for this survey were those aged 60 or older with local household registrations at the time of the interview. In total, 7070 individuals were included in the final sample. Our study focused on respondents in the rural area with a sample of $\mathrm{N}=5514$.

\section{Dependent variable}

In our study, suicidal ideation was assessed by using a question of "Have you ever seriously thought about committing suicide in the past 12 months?" from the US National Comorbidity Survey [28]. If the answer was "yes", suicidal ideation was coded as " 1 ". If the answer was "no", suicidal ideation was coded as " 0 ".

\section{Independent variable}

The social demographic characteristics included gender, age, marital status, education level, self-rated economic status and debt status. Gender was categorized as male and female. The age of the participants was grouped into three types: 60-69, 70-79 and 80 years. Marital status was categorized into married and others (include 
unmarried, divorced and widowed). Education level was classified into three categories: illiterate, primary school and middle school or above. Self-rated economic status was measured by asking participants to rate their economic status with four options: wealthy and not worried about livelihood, not wealthy but not worried about livelihood, not wealthy and worried about livelihood, poor and worried about livelihood. Response of "wealthy and not worried about livelihood" was identified into the "good" category, and other responses were recoded as "moderate or bad". Debt status was measured by a question of "Do your family have any debts at present?". The answer included "yes" and "no".

Family-related factors included living arrangement, relationship with family, stress of daily life, and negative life events. Living arrangement was divided into "living alone" and "living with others". We asked participants with a question of "How do you feel about the relationship with your family?" and the answer was categorized into "good" and "moderate or bad". Stress of daily life was assessed by asking participants rate their life stress with five options: very high, high, moderate, low, none. We recorded the former four responses as "yes" and the last one as "no". Negative life events were assessed by asking a question of "Have you encountered any major setbacks or unexpected misfortunes in your life and work in the past two years, such as natural hazards, diseases, accidents, death of a family member, lawsuits, dispute, etc.?" The response options included "yes" and "no".

Physical health status included self-rated health, noncommunicable chronic diseases (NCDs) condition, and activities of daily living (ADL) status. Self-rated health status was assessed by asking the participants rate their health condition with a single question: "would you say that your health has on the whole been excellent, good, moderate, bad, or very bad in a month?" Response of "excellent" and "good" was classified into the "good" category, and remaining were recoded as "moderate or bad". We collected the presence of non-communicable chronic diseases (NCDs) of the participants by the question of "Have you been diagnosed with hypertension/diabetes/ chronic obstructive pulmonary disease/cancer/periodontitis/other chronic diseases by a doctor?". The response to presence of NCDs included "yes" and "no". Activities of daily living were assessed using the Activities of Daily Living Scale (ADLs). ADLs is a scale with 14 terms that refers to peoples' daily self-care activities which is used as a measurement of people's functional status, especially in people with injuries or disabilities or older adults [29]. Total score of ADL ranges from 14 to 56, and the higher total score corresponds to worse ADL status [30]. The total score of ADL can be divided into 2 levels: normal (14 scores), and disabled (>14 scores).
Loneliness was assessed with the University of California Los Angeles Loneliness Scale (ULS) short-form (ULS8 ), which consists of eight questions and each question is scored from 1 to 4 [31]. The total score of ULS-8 ranged from 8 to 32, with a high score indicating greater loneliness.

Psychological distress was measured by the Kessler Psychological Distress Scale (K10), which is an effective tool to evaluate people's psychological status designed by Kessler, Andrews and so on [32]. It is a scale with 10-items regarding people's level of anxiety and depression symptoms. The reliability and validity of K10 in Chinese-language version was demonstrated to be good [33]. The total score of $\mathrm{K} 10$ ranges from 10 to 50, and the higher score means more severe psychological distress.

Life Satisfaction was measured by the Satisfaction with Life Scale (SWLS) which was developed by Diener [34]. The scale includes 5 items and participants were asked to answer each item on a 7-point Likert scale (from $1=$ strongly disagree to $7=$ strongly agree). The total score ranges from 5 to 35 , and the higher total score refers to higher life satisfaction.

\section{Statistical analysis}

All statistical analyses were performed using SPSS 24.0. First, we presented descriptive statistics of the sample by gender, using the $t$ test and Chi-square test to examine the difference between males and females. Then, binary logistic regression with one unadjusted model and one adjusted model were employed to examine the influencing factors associated with suicidal ideation among elderly. Finally, two separate binary logistic regression models were performed to determine the factors associated with suicidal ideation among males and females, respectively. All reported CIs were calculated at the 95\% level. Statistical significance was set at the $5 \%$ level.

\section{Results \\ Sample description}

Table 1 shows the characteristics of the sample and the prevalence of suicidal ideation among rural elderly. Among the total 5514 rural elderly, 2366 were males $(42.9 \%)$ and 3148 were females $(57.1 \%)$. More than half of the participants aged 60-69 years (53.8\%). Most of them were currently married $(80.8 \%)$. As for education level, 2164 (39.2\%) were illiterate, 2277 (41.3\%) finished primary education, and 1073 (19.5\%) finished junior school or above education. Regarding economic status, 856 (15.5\%) reported good self-rated economic and 310 (5.6\%) had debts. In terms of physical health status, 2636 (47.8\%) reported moderate or bad self-rated health, 3796 (68.8\%) suffered from NCDs, and 1418 (25.7\%) was disabled. Besides, 775 (14.1\%) lived alone, 296 (1.1\%) had 
Table 1 Characteristics of rural elderly by gender

\begin{tabular}{|c|c|c|c|c|c|}
\hline Characteristics & Total $N(\%)$ & Male $N(\%)$ & Female N (\%) & $x^{2} / t$ & $P$ value \\
\hline Observations & 5514 & $2366(42.9)$ & $3148(57.1)$ & & \\
\hline Suicidal ideation & & & & 28.535 & $<0.001$ \\
\hline No & $5089(92.3)$ & $2236(94.5)$ & $2853(90.6)$ & & \\
\hline Yes & $425(7.7)$ & $130(5.5)$ & $295(9.4)$ & & \\
\hline Age & & & & 21.988 & $<0.001$ \\
\hline $60 \sim$ & $2964(53.8)$ & $1195(50.5)$ & $1769(56.2)$ & & \\
\hline $70 \sim$ & $2063(37.4)$ & $968(40.9)$ & $1095(34.8)$ & & \\
\hline $80 \sim$ & $487(8.8)$ & $203(8.6)$ & $284(9.0)$ & & \\
\hline Marital status & & & & 82.862 & $<0.001$ \\
\hline Married & $4454(80.8)$ & $2043(86.3)$ & $2411(76.6)$ & & \\
\hline Others & $1060(19.2)$ & $323(13.7)$ & $737(23.4)$ & & \\
\hline Education level & & & & 749.074 & $<0.001$ \\
\hline Illiterate & $2164(39.2)$ & $477(20.2)$ & $1687(53.6)$ & & \\
\hline Primary school & $2277(41.3)$ & $1140(48.2)$ & $1137(36.1)$ & & \\
\hline Junior school or above & $1073(19.5)$ & $749(31.7)$ & $324(10.3)$ & & \\
\hline Self-rated economic & & & & 16.279 & $<0.001$ \\
\hline Good & $856(15.5)$ & $421(17.8)$ & $435(13.8)$ & & \\
\hline Moderate or poor & $4658(84.5)$ & $1945(82.2)$ & $2713(86.2)$ & & \\
\hline Debts & & & & 3.564 & 0.059 \\
\hline No & $5204(94.4)$ & 2217 (93.7) & $2987(94.9)$ & & \\
\hline Yes & $310(5.6)$ & $149(6.3)$ & $161(5.1)$ & & \\
\hline Self-rated health & & & & 19.989 & $<0.001$ \\
\hline Good & $2878(52.2)$ & $1317(55.7)$ & $1561(49.6)$ & & \\
\hline Moderate or bad & $2636(47.8)$ & $1049(44.3)$ & $1587(50.4)$ & & \\
\hline NCDs & & & & 52.919 & $<0.001$ \\
\hline No & $1718(31.2)$ & $861(36.4)$ & $857(27.2)$ & & \\
\hline Yes & 3796 (68.8) & 1505 (63.6) & $2291(72.8)$ & & \\
\hline $\mathrm{ADL}$ & & & & 28.962 & $<0.001$ \\
\hline Normal & $4096(74.3)$ & $1844(77.9)$ & $2252(71.5)$ & & \\
\hline Disabled & $1418(25.7)$ & $522(22.1)$ & $896(28.5)$ & & \\
\hline Living arrangement & & & & 43.806 & $<0.001$ \\
\hline Alone & $775(14.1)$ & $248(10.5)$ & $527(16.7)$ & & \\
\hline Others & 4739 (85.9) & 2118 (89.5) & $2621(83.3)$ & & \\
\hline Relationship with family & & & & 0.712 & 0.399 \\
\hline Good & 5218 (94.6) & $2232(94.3)$ & $2986(94.9)$ & & \\
\hline Moderate or bad & $296(5.4)$ & $134(5.7)$ & $162(5.1)$ & & \\
\hline Stress of daily life & & & & 0.086 & 0.769 \\
\hline No & $2833(51.4)$ & $1221(51.6)$ & $1612(51.2)$ & & \\
\hline Yes & $2681(48.6)$ & $1145(48.4)$ & $1536(48.8)$ & & \\
\hline Negative life events & & & & 0.022 & 0.882 \\
\hline No & 4919 (89.2) & 2109 (89.1) & $2810(89.3)$ & & \\
\hline Yes & $595(10.8)$ & $257(10.9)$ & $338(10.7)$ & & \\
\hline ULS-8 & $11.09 \pm 4.59$ & $11.15 \pm 4.59$ & $11.05 \pm 4.59$ & 0.760 & 0.447 \\
\hline Psychological distress & $15.54 \pm 6.87$ & $14.72 \pm 6.58$ & $16.15 \pm 7.02$ & -7.754 & $<0.001$ \\
\hline Life satisfaction & $30.55 \pm 5.13$ & $30.59 \pm 5.18$ & $30.52 \pm 5.10$ & 0.497 & 0.619 \\
\hline
\end{tabular}


moderate or bad relationship with family, 2681 (48.6\%) had stress of daily life, and 595 (10.8\%) experienced setbacks or unfortunate events in the past two years. The elderly's ULS-8 mean score was $11.09 \pm 4.59$, K10 mean score was $15.54 \pm 6.87$ and SWLS mean score was $30.55 \pm 5.13$.

The result showed that $425(7.7 \%)$ elderly reported suicidal ideation within the past 12 months, including 130 males (5.5\%) and 295 females (9.4\%). There was statistically significant difference in suicidal ideation between rural males and females $(P<0.001)$. Besides, age $(P<0.001)$, marital status $(P<0.001)$, education level $(P<0.001)$, self-rated economic $(P<0.001)$, self-rated health $(P<0.001)$, NCDs $(P<0.001)$, ADL status $(P<0.001)$, living arrangement $(P<0.001)$ and psychological distress $(P<0.001)$ were also significantly different between males and females.

\section{Factors associated with suicidal ideation among rural male seniors}

Table 2 shows the factors related to suicidal ideation among males. The results of adjusted binary logistic regression model revealed the following factors were statistically associated with suicidal ideation $(P<0.05)$, including education level, debts, stress of daily life, loneliness and psychological distress. Among males, those who were illiterate (adjusted $\mathrm{OR}=1.98, P<0.05$ ) and finished primary education (adjusted $\mathrm{OR}=1.89, P<0.05$ ), had debts (adjusted $\mathrm{OR}=1.98, P<0.05$ ), had stress of daily life (adjusted $\mathrm{OR}=1.70, P<0.05$ ), had greater feeling of

Table 2 Factors associated with the suicidal ideation among rural males

\begin{tabular}{|c|c|c|c|c|}
\hline \multirow[t]{2}{*}{ Characteristics } & \multicolumn{2}{|c|}{ Suicidal ideation (N/\%) } & \multirow{2}{*}{$\begin{array}{l}\text { Unadjusted model } \\
\text { OR }(95 \% \mathrm{Cl})\end{array}$} & \multirow{2}{*}{$\begin{array}{l}\text { Adjusted model } \\
\text { OR }(95 \% \mathrm{Cl})\end{array}$} \\
\hline & No & Yes & & \\
\hline Variables & $2236(94.5)$ & $130(5.5)$ & & \\
\hline Age (reference: 60 ) & & & & - \\
\hline $70 \sim$ & $918(94.8)$ & $50(5.2)$ & $0.86(0.59-1.25)$ & \\
\hline $80 \sim$ & $194(95.6)$ & $9(4.4)$ & $0.73(0.36-1.49)$ & \\
\hline \multicolumn{5}{|l|}{ Marital status (reference: married) } \\
\hline Others & $296(91.6)$ & $27(8.4)$ & $1.72(1.11-2.67)^{*}$ & $1.18(0.69-2.02)$ \\
\hline \multicolumn{5}{|c|}{ Education level (reference: junior school or above) } \\
\hline Illiterate & $444(93.1)$ & $33(6.9)$ & $2.07(1.22-3.50)^{* *}$ & $1.98(1.08-3.65)^{*}$ \\
\hline Primary school & $1069(93.8)$ & $71(6.2)$ & $1.85(1.17-2.92)^{* *}$ & $1.89(1.11-3.20)^{*}$ \\
\hline \multicolumn{5}{|l|}{ Self-rated economic (reference: good) } \\
\hline Moderate or poor & $1822(93.7)$ & $123(6.3)$ & $3.99(1.85-8.62)^{* * *}$ & $1.35(0.59-3.06)$ \\
\hline \multicolumn{5}{|l|}{ Debts (reference: no) } \\
\hline Yes & $115(77.2)$ & $34(22.8)$ & $6.53(4.23-10.08)^{* * *}$ & $1.98(1.14-3.42)^{*}$ \\
\hline \multicolumn{5}{|l|}{ Self-rated health (reference: good) } \\
\hline Bad & $956(91.1)$ & $93(8.9)$ & $3.37(2.28-4.97)^{* * *}$ & $1.29(0.80-2.10)$ \\
\hline \multicolumn{5}{|l|}{ NCDs (reference: no) } \\
\hline Yes & $1400(93.0)$ & $105(7.0)$ & $2.51(1.61-3.91)^{* * *}$ & $1.63(0.97-2.73)$ \\
\hline \multicolumn{5}{|l|}{ ADL (reference: normal) } \\
\hline Disabled & $478(91.6)$ & $44(8.4)$ & $1.88(1.29-2.74)^{* *}$ & $0.64(0.39-1.03)$ \\
\hline Living arrangement (reference: others) & & & & - \\
\hline Alone & $230(92.7)$ & $18(7.3)$ & $1.40(0.84-2.35)$ & \\
\hline \multicolumn{5}{|l|}{ Relationship with family (reference: good) } \\
\hline $\mathrm{Bad}$ & $106(79.1)$ & $28(20.9)$ & $5.52(3.48-8.75)^{* * *}$ & $1.02(0.55-1.88)$ \\
\hline \multicolumn{5}{|l|}{ Stress of daily life (reference: no) } \\
\hline Yes & $1039(90.7)$ & $106(9.3)$ & $5.09(3.24-7.99)^{* * *}$ & $1.70(1.01-2.87)^{*}$ \\
\hline \multicolumn{5}{|l|}{ Negative life events (reference: no) } \\
\hline Yes & $216(84.0)$ & $41(16.0)$ & $4.31(2.90-6.40)^{* * *}$ & $1.42(0.88-2.31)$ \\
\hline ULS-8 & $10.78 \pm 4.11$ & $17.52 \pm 7.09$ & $1.22(1.19-1.26)^{* * *}$ & $1.09(1.05-1.14)^{* * *}$ \\
\hline Psychological distress & $14.12 \pm 5.87$ & $25.04 \pm 9.15$ & $1.17(1.14-1.19)^{* * *}$ & $1.09(1.06-1.13)^{* * *}$ \\
\hline Life satisfaction & $30.88 \pm 4.79$ & $25.51 \pm 8.19$ & $0.88(0.86-0.90)^{* * *}$ & $0.98(0.95-1.01)$ \\
\hline
\end{tabular}

${ }^{*} P<0.05 ;{ }^{* *} P<0.01 ;{ }^{* * *} P<0.001$ 
loneliness (adjusted $\mathrm{OR}=1.09, P<0.001$ ) and had severer psychological distress (adjusted $\mathrm{OR}=1.09, \quad P<0.001$ ) were positively significantly associated with suicidal ideation.

\section{Factors associated with suicidal ideation among rural female seniors}

The results of adjusted binary logistic regression model among females are represented in Table 3 . The results showed that education level, debts, stress of daily life, negative life events, loneliness, psychological distress and life satisfaction were statistically associated with suicidal ideation $(P<0.05)$. For females, those who were illiterate (adjusted $\mathrm{OR}=2.58 P<0.01$ ), had debts (adjusted $\mathrm{OR}=1.96, P<0.01$ ), had stress of daily life (adjusted
$\mathrm{OR}=2.92, P<0.001)$, experienced negative life events in past 2 years (adjusted $\mathrm{OR}=2.42, P<0.001$ ), had greater feeling of loneliness (adjusted $\mathrm{OR}=1.09, \quad P<0.001$ ), had severer psychological distress (adjusted $\mathrm{OR}=1.09$, $P<0.001$ ) and had lower life satisfaction (adjusted $\mathrm{OR}=0.97, P<0.05)$ and were more likely to have experienced suicidal ideation than their counterparts.

\section{Discussion}

Our study showed that the self-reported 12-month prevalence of suicidal ideation was $7.7 \%$ among 5514 rural elderly in Shandong Province, China. According to previous researches, the prevalence of suicidal ideation in rural seniors aged 60 and over in China ranges from 7.1 to $21.5 \%$. A study performed in Hubei Province showed

Table 3 Factors associated with the suicidal ideation among rural females

\begin{tabular}{|c|c|c|c|c|}
\hline \multirow[t]{2}{*}{ Characteristics } & \multicolumn{2}{|c|}{ Suicidal ideation $(N / \%)$} & \multirow{2}{*}{$\begin{array}{l}\text { Unadjusted model } \\
\text { OR }(95 \% \mathrm{Cl})\end{array}$} & \multirow{2}{*}{$\begin{array}{l}\text { Adjusted model } \\
\text { OR }(95 \% \mathrm{Cl})\end{array}$} \\
\hline & No & Yes & & \\
\hline Variables & $2853(90.6)$ & $295(9.4)$ & & \\
\hline Age (reference: 60 ) & & & & - \\
\hline $70 \sim$ & $1001(91.4)$ & $94(8.6)$ & $0.85(0.65-1.10)$ & \\
\hline $80 \sim$ & $260(91.5)$ & $24(8.5)$ & $0.83(0.53-1.30)$ & \\
\hline Marital status (reference: married) & & & & - \\
\hline Others & $655(88.9)$ & $82(11.1)$ & $1.29(0.99-1.69)$ & \\
\hline \multicolumn{5}{|c|}{ Education level (reference: junior school or above) } \\
\hline Illiterate & $1499(88.9)$ & $188(11.1)$ & $2.01(1.24-3.28)^{* *}$ & $2.58(1.47-4.52)^{* *}$ \\
\hline Primary school & $1049(92.3)$ & $88(7.7)$ & $1.35(0.81-2.25)$ & $1.70(0.95-3.05)$ \\
\hline \multicolumn{5}{|l|}{ Self-rated economic (reference: good) } \\
\hline Moderate or poor & $2437(89.8)$ & $276(10.2)$ & $2.48(1.54-3.99)^{* * *}$ & $0.99(0.57-1.71)$ \\
\hline \multicolumn{5}{|l|}{ Debts (reference: no) } \\
\hline Yes & $107(66.5)$ & $54(33.5)$ & $5.75(4.04-8.18)^{* * *}$ & $1.96(1.25-3.07)^{* *}$ \\
\hline \multicolumn{5}{|l|}{ Self-rated health (reference: good) } \\
\hline Bad & $1381(87.0)$ & $206(13.0)$ & $2.47(1.90-3.20)^{* * *}$ & $0.97(0.70-1.35)$ \\
\hline \multicolumn{5}{|l|}{ NCDs (reference: no) } \\
\hline Yes & $2043(89.2)$ & $248(10.8)$ & $2.09(1.52-2.89)^{* * *}$ & $1.13(0.77-1.66)$ \\
\hline \multicolumn{5}{|l|}{ ADL (reference: normal) } \\
\hline Disabled & $766(85.5)$ & $130(14.5)$ & $2.15(1.68-2.74)^{* * *}$ & $1.18(0.87-1.60)$ \\
\hline Living arrangement (reference: others) & & & & - \\
\hline Alone & $467(88.6)$ & $60(11.4)$ & $1.30(0.97-1.76)$ & \\
\hline \multicolumn{5}{|l|}{ Relationship with family (reference: good) } \\
\hline Bad & $116(71.6)$ & $46(28.4)$ & $4.36(3.03-6.28)^{* * *}$ & $0.78(0.48-1.26)$ \\
\hline \multicolumn{5}{|l|}{ Stress of daily life (reference: no) } \\
\hline Yes & $1284(83.6)$ & $252(16.4)$ & $7.16(5.14-9.98)^{* * *}$ & $2.92(2.02-4.22)^{* * *}$ \\
\hline \multicolumn{5}{|l|}{ Negative life events (reference: no) } \\
\hline Yes & $229(67.8)$ & $109(32.2)$ & $6.72(5.11-8.82)^{* * *}$ & $2.42(1.75-3.37)^{* * *}$ \\
\hline ULS-8 & $10.51 \pm 3.93$ & $16.32 \pm 6.68$ & $1.21(1.19-1.24)^{* * *}$ & $1.09(1.06-1.12)^{* * *}$ \\
\hline Psychological distress & $15.24 \pm 6.13$ & $24.93 \pm 8.76$ & $1.17(1.15-1.18)^{* * *}$ & $1.09(1.07-1.12)^{* * *}$ \\
\hline Life satisfaction & $30.94 \pm 4.53$ & $26.43 \pm 7.78$ & $0.88(0.86-0.90)^{* * *}$ & $0.97(0.95-1.00)^{*}$ \\
\hline
\end{tabular}

${ }^{*} P<0.05 ;{ }^{* *} P<0.01 ;{ }^{* * *} P<0.001$ 
the prevalence of 12-month suicidal ideation among rural seniors was 7.1\% [35]. A study conducted in Hunan Province, the reported suicidal ideation among rural elderly was 14.5\% [20]. Another study from Hunan Province showed that the prevalence of suicidal ideation among rural elderly was $21.5 \%$ [36]. Different levels of socioeconomic development, research backgrounds, sample sizes and applied measures might explain the variations of the prevalence of suicidal ideation between our study and those studies mentioned above.

We also found that there was a significant gender difference towards suicidal ideation among elderly and the 12-month prevalence of suicidal ideation in females was significantly higher than that in males, which was in accordance with the findings from previous studies [10, 36, 37]. There might be three explanations for this finding. The first explanation is that in many Chinese rural families, females are dependent on males and they have to obey their husbands, their status is low in families. This lack of individual social identity and family status may increase the risk for psychological problems such as stress or depression which could then lead to the occurrence of suicidal ideation among these females. Second, rural females not only undertake more responsibility of taking care of the family, but also suffer more pressure from society and family. In such situation, females may be overwhelmed by negative emotion, feeling of hopelessness, lack of social support, problem solving, and coping skills in dealing with their stressful life event. Third, females are generally more vulnerable than males and have poor psychological tolerance when confronted with negative life events such as loss of a family or be diagnosed with cancer. Previous study illustrated that women more often reported a strong negative impact on psychological well-being when they encountered adverse life events [50]. So, once something bad happened to them, females are more likely to have suicidal ideation than males.

In this study, we revealed the different influencing factors of suicidal ideation between rural older males and females, few of which were mentioned in previous studies. And several influence factors were found to be associated with suicidal ideation in both males and females, such as education level, debts, stress of daily life, loneliness and psychological distress. Lower education level was an independent risk factor for suicidal ideation; this finding was consistent with the conclusions from some studies conducted in China, French and Korea [12, 38, 39]. Generally speaking, adults in poor economic circumstances were more likely to exhibit suicidal ideation than those in good economic circumstances. Many studies had demonstrated that population in debt were associated with higher incidence of suicidal ideation [40,
41], and this was also true for Chinese elderly. Another study revealed that financial loss rather than low income remained a significant correlated of suicidal ideation after controlling for depression [42]. Our findings were also in line with the results of previous researches, which suggested that loneliness was significantly correlated with suicidal ideation [43-45]. In addition, we also found that psychological distress was significantly associated with suicidal ideation among elderly, which was in agreement with previous studies [46, 47]. Elderly with higher score of psychological distress were more likely to have suicidal ideation, which implied that seniors began to consider that life was not worth living when they were in bad mental health. Furthermore, stress was also an important factor associated with suicidal ideation. Previous study suggested that suicide could function as an escape mechanism for avoiding stressful situations [48]. Similarly, our study showed that stress of daily life was significantly correlated with suicidal ideation in both males and females. These findings indicated that more attention should be paid to develop interventions targeting the at-risk subgroups to prevent suicidal ideation among the elderly in China.

However, two factors correlated with suicidal ideation were found to be different by gender. Among the females, negative life event was significantly associated with suicidal ideation, which was not found in males. People who encountered negative life events often experience psychological problems which contribute to suicidal ideation. The difference between males and females could be explained by the fact that females were more vulnerable when they experienced negative life events compared with males. And the role of female as a socially disadvantaged group made them more susceptible to crisis and negative emotions in setbacks, which made them more likely to have suicidal ideation. Another factor that was found to differ across gender was life satisfaction. Previous study showed that life satisfaction was inversely correlated with suicidal ideation among college students and this correlation tended to be stronger among the seniors than younger people [49]. In our study, females with lower life satisfaction had more likelihood to occur suicidal ideation, which was not found in males. One possible explanation might be that females suffered more pressure in taking care of family and dealing with household chores, so they had a stronger desire to live a good life. In our study, overall females reported lower life satisfaction than males, the imbalance of high life stress and low satisfaction with life might heighten the risk of suicidal ideation among these females. These findings implied that prevention by gender should be considered for preventing suicidal ideation and we should pay more attention to female elderly. 
There are some limitations in this study. Firstly, the cross-sectional nature of our survey precludes us from assessing cause and effect to our results. Secondly, our data were based on self-reported measures such as selfrated economic status, relationship with family, stress of daily life, negative life event and NCDs; false or inaccurate response from participants may have led to recall bias or reporting bias. And measurement errors might exist because most variables were measured with single question. All of these may have influenced the validity of the results of our study. Thirdly, our main dependent variable was estimated via a single question instead of a standardized instrument, which could not fully reflect elderly's diverse perspectives regarding suicidal ideation.

\section{Conclusions}

Our study demonstrated that there was a significant gender difference towards suicidal ideation among rural elderly in Shandong, China. The common risk factors for suicidal ideation were education level, debts, stress of daily life, loneliness and psychological distress in males and females. We also found that negative life events and life satisfaction were significantly correlated with suicidal ideation in females but not in males. Thus, gender difference should be considered when medical practitioners and public health workers seek to prevent and manage suicidal ideation among rural elderly; more attention should be paid to females who had encountered negative life event or had lower life satisfaction.

\section{Abbreviation}

NCDs: non-communicable chronic diseases; ADL: Activity of Daily Living; ULS8: University of California Los Angeles Loneliness Scale (ULS) short-form; OR: odds ratio; $\mathrm{Cl}$ : confidence interval.

\section{Acknowledgements}

We would like to thank the support of Shandong University Center for Health Economics Experiment and Public Policy Research. We also thank all participants and staff at the study sites for their cooperation.

\section{Authors' contributions}

All authors made substantial contributions to this study. LL analyzed the data and drafted the manuscript; LX provided important guidance on the writing and made great contributions in the process of revising; $X \mathrm{~L}$ and $L S$ reviewed the paper; $J L$ designed and supervised the questionnaire; $W Q$ and $J Z$ contributed significantly in the analysis and revision of the draft; $X J, Y W, Y X, Y L$ and $\mathrm{AJ}$ also gave many valuable comments on the draft. All authors read and approved the final manuscript.

\section{Funding}

This study was funded by three grants from the National Natural Science Foundation of China (Grant Numbers: 71673169, 71673170 and 71974118). The funding body had no role in design of study, data collection and analysis, interpretation of data or writing of manuscript.

\section{Availability of data and materials}

The datasets used in the current study are not publicly available due to the confidential policy, but are available from the corresponding author on reasonable request.
Ethics approval and consent to participate Not applicable.

\section{Consent for publication}

All the authors have given consent for the publication.

\section{Competing interests}

The authors declare that they have no competing interests.

\section{Author details}

${ }^{1}$ School of Public Health, Shandong University, Jinan 250012, China. ${ }^{2}$ NHC, Key Laboratory of Health Economics and Policy Research, Shandong University, Jinan 250012, China. ${ }^{3}$ Center for Health Economics Experiment and Public Policy Research, Shandong University, Jinan 250012, China. ${ }^{4}$ Department of Nursing Management of Qilu Hospital, Shandong University, Jinan 250012, China.

Received: 12 September 2019 Accepted: 31 December 2019 Published online: 14 January 2020

\section{References}

1. WHO. Mental health, Suicide data. https://www.who.int/mental_health/ prevention/suicide/suicideprevent/en/. Accessed 27 June 2019.

2. WHO. Global health observatory $(\mathrm{GHO})$ data, suicide rate. https://www. who.int/gho/mental_health/suicide_rates/en/. Accessed 27 June 2019.

3. WHO. Preventing suicide: A global imperative. 2014. https://apps.who.int/ iris/bitstream/handle/10665/131056/9789241564779_eng.pdf;jsessionid =F95217E38E4BB52696EF50BC6CF7B592? sequence=1. Accessed 27 June 2019.

4. Phillips MR, Li X, Zhang Y. Suicide rates in China, 1995-99. The Lancet. 2002;359(9309):835-40.

5. Chan HL, Liu CY, Chau YL, Chang CM. Prevalence and association of suicide ideation among Taiwanese elderly-a population-based crosssectional study. Chang Gung Med J. 2011;34(2):197-204.

6. Kim SH. Suicidal ideation and suicide attempts in older adults: influences of chronic illness, functional limitations, and pain. Geriatr Nurs. 2016:37(1):9-12.

7. Li X, Xiao Z, Xiao S. Suicide among the elderly in mainland China. Psychogeriatrics. 2009;9(2):62-6.

8. Yip PSF, Liu KY, Hu J, Song XM. Suicide rates in China during a decade of rapid social changes. Soc Psychiatry Psychiatr Epidemiol. 2005;40(10):792-8.

9. Yip PSF, Callanan C, Yuen HP. Urban/rural and gender differentials in suicide rates: east and west. J Affect Disorders. 2000;57(1):99-106.

10. Dong Y, Huang F, Hu G, Liu Y, Zheng R, Zhang Q, et al. The prevalence of suicidal ideation among the elderly in China: a meta-analysis of 11 crosssectional studies. Compr Psychiatry. 2014;55(5):1100-5.

11. Chiu HFK, Dai J, Xiang YT, Chan SSM, Leung T, Yu X, et al. Suicidal thoughts and behaviors in older adults in rural China: a preliminary study. Int J Geriatr Psychiatry. 2012;27(11):1124-30.

12. Dai J, Chiu HFK, Conner KR, Chan SSM, Hou ZJ, Yu X, et al. Suicidal ideation and attempts among rural Chinese aged 16-34 years-sociodemographic correlates in the context of a transforming China. J Affect Disorders. 2011;130(3):438-46.

13. Cheung YB, Law CK, Chan B, Liu KY, Yip PSF. Suicidal ideation and suicidal attempts in a population-based study of Chinese people: risk attributable to hopelessness, depression, and social factors. J Affect Disorders. 2006;90(2):193-9.

14. Yung-Chieh Y, Ming-Jen $Y$, Mei-Sang Y, For-Wey L, Chun-Hua S, Cheng-Yi $\mathrm{H}$, et al. Suicidal ideation and associated factors among communitydwelling elders in Taiwan. Psychiatry Clin Neurosci. 2010;59(4):365-71.

15. Lee $H$, Hahm M, Park E. Differential association of socio-economic status with gender- and age-defined suicidal ideation among adult and elderly individuals in South Korea. Psychiatry Res. 2013;210(1):323-8.

16. Kwon $\mathrm{H}$, Jeong J, Choi M. Social Relationships and Suicidal Ideation Among the Elderly Who Live Alone in Republic of Korea: A Logistic Model. INQUIRY: The Journal of Health Care Organization, Provision, and Financing. 2018:55:1402622889. 
17. Ge D, Sun L, Zhou C, Qian Y, Zhang L, Medina A. Exploring the risk factors of suicidal ideation among the seniors in Shandong, China: a path analysis. J Affect Disorders. 2017;207:393-7.

18. Almeida OP, Draper B, Snowdon J, Lautenschlager NT, Pirkis J, Byrne G, et al. Factors associated with suicidal thoughts in a large community study of older adults. Br J Psychiatry. 2012;201(6):466-72.

19. Dennis M, Baillon S, Brugha T, Lindesay J, Stewart R, Meltzer H. The influence of limitation in activity of daily living and physical health on suicidal ideation: results from a population survey of Great Britain. Soc Psychiatry Psychiatr Epidemiol. 2009;44(8):608-13.

20. Xu H, Qin L, Wang J, Zhou L, Luo D, Hu M, et al. A cross-sectional study on risk factors and their interactions with suicidal ideation among the elderly in rural communities of Hunan, China. BMJ Open. 2016;6(4):e10914.

21. Chen Y, Chien-Chang WuK, Yousuf S, Yip PSF. Suicide in Asia: opportunities and challenges. Epidemiol Rev. 2012;34(1):129-44.

22. Wei S, Yan H, Chen W, Liu L, Bi B, Li H, et al. Gender-specific differences among patients treated for suicide attempts in the emergency departments of four general hospitals in Shenyang, China. Gen Hosp Psychiatry. 2013;35(1):54-8

23. Chou $\mathrm{CH}$, Ko HC, Wu JY, Cheng C. The prevalence of and psychosocial risks for suicide attempts in male and female college students in Taiwan. Suicide Life-Threat. 2013:43(2):185-97.

24. Park S. Gender-specific factors of suicide ideation among adolescents in the Republic of Korea: a nationally representative population-based study. Arch Psychiatr Nurs. 2013;27(5):253-9.

25. Ibrahim N, Amit N, Che Din N, Ong HC. Gender differences and psychological factors associated with suicidal ideation among youth in Malaysia. Psychol Res Behav Manag. 2017;10:129-35.

26. Cui S, Cheng Y, Xu Z, Chen D, Wang Y. Peer relationships and suicide ideation and attempts among Chinese adolescents. Child. 2011;37(5):692-702

27. Chiu Y, Tseng C, Lin F. Gender differences and stage-specific influence of parent-adolescent conflicts on adolescent suicidal ideation. Psychiatry Res. 2017;255:424-31.

28. Kessler RCBPBG. Trends in suicide ideation, plans, gestures, and attempts in the United States, 1990-1992 to 2001-2003. JAMA 2005;293(20):2487-95

29. Katz S, Ford AB, Moskowitz RW, Jackson BA, Jaffe MW. Studies of illness in the aged. The index of Adl: a standardized measure of biological and psychosocial function. JAMA. 1963;12(185):914-9.

30. Huang W, Xiao-Jiao GE, Hou S. Ability of daily living and its influencing factors among rural elderly in Dabieshan Mountain area. Chin J Public Health. 2012;28(7):884-6.

31. Hays R, DiMatteo MR. A short-form measure of loneliness. J Pers Assess. 1987;51(1):69-81.

32. Kessler RC, Andrews G, Colpe LJ, Hiripi E, Mroczek DK, Normand SLT, et al. Short screening scales to monitor population prevalences and trends in non-specific psychological distress. Psychol Med. 2002;32(6):959-76.

33. Zhou CCJWT. Reliability and validity of 10-item Kessler Scale (K10) Chinese version in evaluation of mental health status of Chinese population. Chin J Clin Psychol. 2008;16(06):627-9 (in Chinese).
34. Diener EERLR The satisfaction with life scale J Pers Assess. 1985;49(1):71-5.

35. Cheng $\mathrm{LH}$, Chen $\mathrm{H}$, Zheng ML. Association of suicidal ideation and family factors among rural elderly. Chin J Public Health. 2013;29(02):157-9.

36. Zhen-Hua LI, Xiao SY. Suicidal behavior among elderly in a rural community of Human Province. Chin Ment Health J. 2011;25(12):949-54.

37. Fu ZHFSSZ. Self-attribution of suicide ideation in a rural sample of Liuyang, Hunan China. Chin J Clin Psychol. 2007;15(1):78-80.

38. Husky MM, Guignard R, Beck F, Michel G. Risk behaviors, suicidal ideation and suicide attempts in a nationally representative French sample. J Affect Disorders. 2013;151(3):1059-65.

39. Chin YR, Lee HY, So ES. Suicidal ideation and associated factors by sex in Korean adults: a population-based cross-sectional survey. Int J Public Health. 2011;56(4):429-39.

40. Hintikka J, Kontula O, Saarinen P, Tanskanen A, Koskela K, Viinamäki H. Debt and suicidal behaviour in the Finnish general population. Acta Psychiat Scand. 1998;98(6):493-6.

41. Meltzer H, Bebbington P, Brugha T, Jenkins R, McManus S, Dennis MS. Personal debt and suicidal ideation. Psychol Med. 2011;41(4):771-8.

42. Turvey C, Stromquist A, Kelly K, Zwerling C, Merchant J. Financial loss and suicidal ideation in a rural community sample. Acta Psychiatr Scand. 2002;106(5):373-80

43. Stravynski ABR. Loneliness in relation to suicide ideation and parasuicide: a population-wide study. Suicide Life-Threat. 2001;31(1):32-40.

44. Stickley A, Koyanagi A. Loneliness, common mental disorders and suicidal behavior: findings from a general population survey. J Affect Disorders. 2016;197:81-7

45. Chang EC, Sanna LJ, Hirsch JK, Jeglic EL. Loneliness and negative life events as predictors of hopelessness and suicidal behaviors in hispanics: evidence for a diathesis-stress model. J Clin Psychol. 2010;66(12):1242-53.

46. Puuskari V, Aalto-Setälä T, Komulainen E, Marttunen M. Suicidal ideation, suicide attempts, and psychological distress among intoxicated adolescents in the pediatric emergency department. Nord J Psychiatry. 2017;72(2):1.

47. Fujita K, Yong R, Sasaki H, Kaneko Y, Eboshida A, Motohashi Y. Psychological distress as a predictor of suicide ideation among the communitydwelling elderly. Gerontologist. 2016;56:563-4.

48. Fergusson DM, Woodward LJ, Horwood LJ. Risk factors and life processes associated with the onset of suicidal behaviour during adolescence and early adulthood. Psychol Med. 2000;30(1):23-39.

49. Liu $Y X$, Huang WQ, Zhu WE. Suicidal ideation to satisfaction with life and happiness in college freshmen. Chin Ment Health J. 2012;26(03):235-8.

50. Seematter-Bagnoud L, Karmaniola A, Santos-Eggimann B. Adverse life events among community-dwelling persons aged $65-70$ years: gender differences in occurrence and perceived psychological consequences. Soc Psychiatry Psychiatr Epidemiol. 2010;45(1):9-16.

\section{Publisher's Note}

Springer Nature remains neutral with regard to jurisdictional claims in published maps and institutional affiliations.

\footnotetext{
Ready to submit your research? Choose BMC and benefit from:

- fast, convenient online submission

- thorough peer review by experienced researchers in your field

- rapid publication on acceptance

- support for research data, including large and complex data types

- gold Open Access which fosters wider collaboration and increased citations

- maximum visibility for your research: over 100M website views per year
}

At BMC, research is always in progress.

Learn more biomedcentral.com/submissions 